\title{
Influence of COVID-19 on Students' Sign Language Learning in a Teacher-Preparation Program in Saudi Arabia: Moving to E-Learning
}

\author{
Omar Alawajee \\ Department of Special Education, College of Sciences and Arts, Qassim University, Ar Rass, Saudi Arabia \\ ORCID: 0000-0003-0540-3629
}

Received: 7 Mar 2021

Accepted: 18 Apr 2021

\begin{abstract}
This research aims to uncover higher education students' experiences regarding sign language learning with online learning platforms and learning experiences during the coronavirus COVID-19 pandemic in one of the teacher-preparation programs in the Kingdom of Saudi Arabia (KSA) as learning the basics of sign language is one of the essential elements in the teacher-preparation program for future teachers to be able to interact with their deaf students. Qualitative research method, structured individual interviews were employed to collect data to understand students' experiences, knowledge, expectations, and thoughts of the impact of the COVID-19 crisis and the sudden and unplanned movement to online teaching tools on their sign language learning and practices. A total of 24 female students enrolled in a special education bachelor program were interviewed in this study. Fifteen participants thought that the COVID-19 crisis influenced their sign language learning and practices, while six of the interviewees reported no impact, and three were not sure. Data revealed some disadvantages, difficulties, and concerns of learning sign language through e-learning tools and some advantages of sign language learning using e-learning tools during the COVID-19 pandemic and are presented alongside examples of the interviewees' statements. This study presented some practice recommendations like integrating digital game-based learning, web and phone applications to practice sign language to endorse effective and innovative sign language learning and practices techniques.
\end{abstract}

Keywords: COVID-19, sign language, teacher-preparation program, online learning, higher education

\section{INTRODUCTION}

\section{COVID-19}

COVID-19 pandemic is one of the biggest crises worldwide that has impacted all learning institutions, such as schools, colleges, and universities (Vasile, 2020). The impact of COVID-19 is limited to students' learning, but it impacts teachers' skills and proficiency in using various digital learning applications and tools. The main change implemented in many learning institutions is the shift from face-to-face learning to online learning. Many scholars approved this as the proper response during the COVID-19 pandemic situation (Adedoyin \& Soykan, 2020; Rohman et al., 2020). Due to this pandemic, today's world is witnessing a substantial scientific revolution and a tangible development in technological innovations, information technologies, and online communications tools between teachers and learners. Thus, E-learning is one of the most important of these innovations that are proliferating, and its success in achieving its goals depends on interaction with peers and content or ask for help, advice, and guidance (Adedoyin \& Soykan, 2020; Anderson, 2020). Universities globally use different modalities to ensure learning is continuing, such as private tools (e.g., WhatsApp, telegram, and Facebook groups), videoconference applications (e.g., Zoom, Google Meet), and e-learning 
platforms (e.g., Blackboard, Moodle, Microsoft Teams) for sending and receiving assignments, discussion, sharing contents, and e-assessment.

There are some advantages of this crisis to our educational system. First, it is a lesson of crisis management to the society and all sectors in the communities, especially to students and workers in education and their family. It became a very challenging time in education history (Toquero, 2020; Trombly, 2020). Secondly, it helps educators and social sectors to share awareness of the importance of positive attitudes toward real issues in the world (Rousseau, \& Deschacht, 2020). Thirdly, this crisis made the need to expand the selfeducation circle clearly for higher education students and for the lectures and meetings to share opinions and discussion rather than lecturing, which is considered one of the best teaching methods for higher education learning (Umarova, 2020). Creating and modifying the independent cognitive process of the students' needs and interests within the university courses curriculums help them to organize their learning using purposeful, planned, and systematic methods of learning regardless of their individuals' differences (Samuseviča \& Striguna, 2017). In addition to these advantages, COVID-19 and its impact on the mental health of students in higher education raise the needs for mental health and other health-related services to the well-being of students and its relation to the academic success of the students (Hunt \& Eisenberg, 2010; Son et al., 2020).

Furthermore, the COVID-19 period becomes a time to strengthen environmental policies and hygiene practices, and environmental health, which may help address future environmental issues (Toquero, 2020). Therefore, some educators and higher education staff started to take advantage of the COVID-19 pandemic to develop education, means, and participation methods. One of these aspects is teacher-preparation in the Universities' programs for children with special needs. Topping, Douglas, and Robertson (2020) reviewed 1540 studies to explore the research literature on the effects of online learning and whether it is better, worse, or the same as a traditional classroom, the face-to-face learning methods. The researchers highlighted that disadvantaged students are more likely to be unable to connect or do not have access to computers at home, so the gap between disadvantaged and other students are more likely to increase within the coronavirus pandemic period. The researchers reported that online learning, in general, has positive effects in 946 studies (61\% of the total number of the reviewed papers) compared to the traditional classroom to art, health, humanities, and science classes and languages and learning a foreign language. This positive effect is similar between the schools' stages (K-12) and positive for students with special needs or ethnic minorities. Nevertheless, the researchers did not include higher education and teacher-preparation programs in their review, which is this paper's aim.

\section{Teacher-Preparation Program for Deaf Students}

Darling-Hammond and Bransford's (2005) study is considered one of the most comprehensive reviews in teaching and teachers-preparation programs and reported that these programs should provide future teachers with opportunities to master content and knowledge and related practice skills. Future teachers should understand learners' needs and their development within the social context alongside subject matter, such as subject-specific pedagogies and curricula, and practising how to create and construe effective instructional, assessment, and supervision strategies. These skills should be the teachers-preparation program's key goals regardless of the learners' subjects, majors, or paths.

On the other hand, there is a massive disconnection between what students learned in the classrooms and the practicum situation as the faculty who teach the courses are not always the same people in supervising practicum, which may lead to difficulties in integrating ideas (Rose, 2006). This disconnection is the unavailability of suitable resources and the school system that supports technological teaching methodologies. Moreover, the shortage of training teachers in using technology tools effectively enhances teaching (Thomas, 2013).

Teacher-preparation program for special education students is defined as the primary industry for a special education teacher to practice special education in institutes and schools and apply its principles (Kang \& Martin, 2018). These programs are carried out by the Faculties of Education through special education departments in different specializations so that future special education teachers will receive well 
preparation culturally, scientifically, pedagogically, and professionally in a balanced manner before being in service (Rowan et al., 2020). One of the main paths that university students can select in special education programs is the deafness path, which aims to prepare them for deaf and hard hearing students. Therefore, the focus of this paper is the preparation of deaf teachers.

Teacher-preparation programs, hearing loss path, on the Saudi Universities focus on teaching strategies for deaf and hard of hearing children, communication methods with them, and the most prominent difficulties or obstacles they may face during the different learning stages (Aldabas, 2015). Furthermore, students in these programs taught how to draw or modify unique curricula, methods, and teaching methods for groups of students who cannot keep pace with the requirements of regular education and education programs, which distinguished the special education services from regular educational programs (Alnahdi \& Anastasiou, 2020).

Besides that, teacher-preparation program, hearing loss path, support special education programs in the community by providing scientific advice and conducting evaluation programs for the programs and curricula offered in the field and educating community members through lectures, seminars, conferences, and workshops that the special education department contributes independently or in cooperation with other institutions (Alajlan, 2017). The department members also support special education research, authorship, translated books, and related training courses inside and outside the university.

Many fields are considered a future career possibility for special education graduates to work in Saudi Arabia. The most critical area of work for a graduate of the special education specialization in the Kingdom is working in administrative or supervisory positions in special education, such as schools or institutions. In addition to this, they can work in teaching or training jobs or trainers in special education. Graduate of the special education programs can work in the governmental sectors, such as work in the ministries of education, social affairs, health, and labor, and even international and semi-governmental organizations and institutions, such as the United Nations Relief and Works Agency (UNRWA), the Red Crescent, the Red Cross, UNICEF, UNESCO. Those trained teachers can also work in early intervention centers and hospitals, a specialist in early intervention in nurseries and kindergartens, and a family counselor in early intervention centers and hospitals and shelter and daycare centers. Nowadays, there are over 24 programs for the teacher-preparation program in special education over the country (Alajlan, 2017). However, these programs are no longer accept new students due to being overstock in finding a job, which leads the governments to close admission in all the governmental bachelor programs. The rest of the students learned through online resources and platforms due to the COVID-19 pandemic.

\section{The Importance of Sign Language in Teacher Education Programs}

In the Arab World, the Unified Arabic Sign dictionary Language has been recognized to be used in all Arab countries, including Saudi Arabia. However, some studies reported that the deaf communities have limited links with other communities (Abdel-Fattah, 2005); therefore, there is limited interaction with the hearing/speaking community, which led to the emergence of some local sign communication. It is a misconception that sign language is the same internationally (Sahoo, Mishra, \& Ravulakollu, 2014). There are about 300 different sign languages (Meir et al., 2010). This is like using the Unified Arabic sign language and the local sign language in Saudi Arabia, the Saudi Arabian sign language. One of the main issues in the education of the deaf in Saudi Arabia is the use of the Unified Arabia Sign language dictionary, whereas the deaf communities denied it. Alternatively, the work on the establishment of the Saudi Sign Dictionary was by the Saudi Society for Hearing Impairment in 2014 following the order of former King Abdullah bin Abdulaziz Al Saud to standardizing sign language and spreading deaf culture. The dictionary currently has more than 750 signs referencing words and phrases in addition to the children's dictionary, which includes the alphabets and numbers. From the researcher's experience, teacher education programs in Saudi Arabia used the unified dictionary as it is old and well established compared to the Saudi Arabian Sign language dictionary. Thus, sign language should be learned through direct interaction with the deaf community rather than from the unified dictionary, as it may not be well preferred to the audience, the deaf students. 
Learning sign language that suits the deaf community is one of the essential aspects of the teacherpreparation program for deaf students regardless of face-to-face or e-learning environments and materials. It should be noted that the foremost skills in deaf Education are the recognition of the right to education throughout life is learning using sign language, reading, writing, the right to ask questions, and have access to resources. However, these cannot be developed if teachers cannot use sign language effectively with the deaf as it is their first and most used language. Future teachers must learn the basics of sign language to interact with their deaf students; as usual, people with severe and profound hearing loss prefer to communicate through sign language (Middleton et al., 2010). However, e-learning and education may become problematic in special education teacher-preparation programs in learning aspects, such as sign language, as students need face-to-face guidance and immediate handy feedback.

Teacher-preparation programs need to provide enough opportunities to promote and encourage effective communication as it is core for interacting with their future teachers and developing their learning and thinking. Therefore, it is vital to present these future teachers with sign language training and make sure they can communicate through sign language in the classroom with their deaf students as needed. There are currently two courses (three credits each) where students can practice sign language with their lectures and professors. The first course focuses on partial and total communication methods, as well as fingerspelling. These courses cover the communication methods with children with hearing loss in terms of the concept, historical development, importance, rationale for use, advantages, and disadvantages of each method) as well as learning and practicing alphabets and numbers in fingerspelling. After completing this course, students are expected to know the basic concepts of communication methods and express numbers and alphabets well using fingerspelling. Therefore, this means that the course focuses on the very basics of sign language. The second course deals with the concept, historical development, rationale, advantages and disadvantages of the sign language and trains and practices primary sign language (i.e., signs related to family, religion, countries, colors, and measurement units). It includes some social signs such as family and religion and some educational signs such as science and mathematics. After completing this course, students may perform necessary communication with each other using sign language. Therefore, in terms of communication with future deaf and hard of hearing students, the teacher-preparation program counts on these two courses, and no other courses are provided as a part of the bachelor's degree plan. Therefore, as universities have turned to online education methods in various ways since the beginning of the COVID-19 crisis, this study attempts to answer the following question: whether turning to distance or online education helped or hindered future teachers from learning practicing sign language.

Therefore, this study has three main objectives. The first is to explore the advantages of sign learning through online tools used during the COVID-19 crisis. The second objective is to better understand the disadvantages, difficulties, and concerns of learning sign language through online tools used during the COVID-19 to be avoided or overcome. The last and foremost objective is to provide pre-teachers preparation programs' developers with some suggestions and recommendations for sign language teaching using an online mode during a crisis-like situation.

\section{METHODS}

This study employed qualitative research methods, which was defines by Creswell (2007), as starting the research "with assumptions, a worldview, the possible use of a theoretical lens, and the study of research problems inquiring into the meaning individuals or groups ascribe to a social or human problem" (p. 37). As this study aims to collect and understand students' experiences, knowledge, expectations, and thoughts, the qualitative research was selected as it was defined to be an appropriate method to study other's feelings, thoughts, and experiences intentionally (Rubin \& Rubin, 1995). Qualitative data collection through interviews was a "way of finding out what others feel and think about their worlds" (Rubin \& Rubin, 1995, p. 1). Furthermore, John Dewey (the Father of modern Pragmatism) believe that experience is the source of knowledge, and he stated that it is "in the sense that the experienced shock of change is the necessary stimulus to the investigating and comparing which eventually produce knowledge" (Dewey, 1921, p. 90). According to him, "Education is reconstruction or reorganization of experience, which adds to the meaning 
of experience and increases the ability to direct subsequent experiences (2004, p. 83, original in 1960). Therefore, the qualitative research method was identified as the best possible data collection for this study. This study concerns students' thoughts and experience of the impact of the COVID-19 crisis and the sudden and unplanned movement to online teaching tools on their sign language learning and practices.

As the procedures and the outcomes of the Qualitative research methods depend on the researcher (Merriam, 2009), the researcher's identity must be acknowledged. The researcher is a male who is a faculty member of the college of art and science, and the target group for this study was students from the college of education, so there is no forced relationship between the researcher and the participants. However, potential personal biases as the role are different, and gender differences are acknowledged and considered when analyzing and interpreting the data. However, since there is no direct relationship with the participants, and the topic is not sensitive, no other potential biases are identified.

\section{Study Design}

Following the completion of the previously mentioned courses, selection/advertising for the interviews were conducted. The researcher told Participants that participation is voluntary, and consent forms were given alone with participation and privacy statements to ensure confidentiality. All personal information, including the university name and the cohort semester, and the participants' details, were available.

\section{Study Sample}

A total of 24 female students participated in this study. The students were enrolled in a special education bachelor program, hearing loss path, at the university in Saudi Arabia. This sample was selected because they received two to three-semester courses ( 3 credits each) of sign language training through online platforms. The limitation of gender is due to two reasons. The researcher executed gender segregation in higher educational institutes in Saudi Arabia (Alwedinani, 2016), and as the special education major no longer has enrolled male students, so there are no currently male students in the Teacher-preparation program. The participants' selection of this qualitative study is purposeful as the researcher intentionally selects them to learn or understand the searched phenomenon, which is usually the practice for qualitative studies (Creswell \& Creswell, 2018; Johnson \& Christensen, 2012).

Table 1. Study Sample

\begin{tabular}{llcc}
\hline \multicolumn{2}{l}{ Variable } & \multicolumn{2}{c}{ Participants $(\mathrm{n}=24)$} \\
\hline Age & & $\mathrm{F}$ & $\%$ \\
& 21 years old & 9 & 37.5 \\
& 22 years old & 10 & 41.66 \\
& 23 years old & 3 & 12.5 \\
& 24 or over & 2 & 8.33 \\
\hline
\end{tabular}

\section{Data Collection}

The data was conducted using a structured individual interview, where students were asked open-ended questions. The questions focus only on how students see the impact of COVID-19 on their sign language learning and practices based on their experiences, knowledge, expectations, and thoughts. The main question was on their experience on how they were taught sign language during the COVID-19 period. The following questions, which is developed based on their answer to the first questions, aim to better understand what it was found to be useful or not, to help readers, university faculties, and policymakers evaluate this style of sign language learning. Data collected using the interpretive methods of qualitative research, which provide self-reflective thoughts, would allow the researcher to collect personal stories of participants and their experiences (Creswell, 2007).

The interviews run using online communication tools due to the social and academic distances placed by COVID-19 on research and social policy and gender differences, which may have cultural sensitivity of the researcher and the participants. Online tools for interviews may provide a comfortable environment in an 
unpretentious setting helping the participants speak freely. The interviews lasted between 8 to 13 minutes as the research questions and aims were identified and implied directly to the interview questions. Participants were free to dismiss answering the interview questions as they wish without giving a reason and remaining a part of the study upon their consent. They were informed of their right to withdraw from the interviews at any point until the categorizing and analyzing of data where it may become hard to connect data, as it would be completely anonymous.

\section{Data Analysis}

Thematic analysis was used for the qualitative data to search for themes (Bryman, 2016). The qualitative data was transformed and transcribed from the online recording into a soft copy written form in complying with the guidelines of analyzing qualitative data (Bryman, 2016; Creswell \& Creswell, 2018). Each interview transcription was coded with a number from 01 to 24 . Transcriptions were clustered into themes, and then sub-themes and the themes were derived from the collected interviews. Finally, the themes and the evidence of their statements are reported in the results and discussion section.

\section{RESULTS AND DISCUSSION}

In terms of the questions of this paper, 15 of the participants (62.5\%) thought that the COVID-19 crisis and the sudden and unplanned movement to online teaching tools (i.e., distance education) influenced their sign language learning and practices (regardless of whether it is positive or not) while six of the interviewees (25\%) reported no impact. The rest of the participants $n=3(12.5 \%)$, were not sure because they did not experience face-to-face sign language learning. Interviewees reported five disadvantages, difficulties, and concerns of learning sign language through online tools used during the COVID-19 crisis and the movement to e-online. It has limited direct engagement with other learners and the faculty members; caused restrictions on their ability to practice sign language with each other; felt uninterested and unmotivated due to the lack of competition, felt unconfident of their ability to use sign language effectively; and been unable observe and imitate of the movements of the hands and the body as well as facial expressions. In contrast, participants reported four advantages of sign language learning using e-online tools during the COVID-19 pandemic. They helped them to develop their technical skills, practice self-learning skills, become independent learners, create an interactive and accessible environment to interact with each other easily, and practice sign language without being afraid of making a mistake or judged by others, allow them to return to the lecture recording to practice sign languages after the lecture. The interviewees' statements included the pros and cons of online tools used during the COVID-19 crisis.

Learning sign language online has some difficulties, such as that it prevents complete and direct engagement between learner and the faculty members and limited the ability to practice sign language with each other. Some participants reported it limited their ability to ask questions and inquiries and share ideas directly and immediately with their instructors. For example, an interviewee (11) indicated:

\footnotetext{
"I think distance education is not suitable for sign language as it hindered me from learning and practicing sign language because learning signs requires transmission and reception of signs and its instructions on how to be made correctly, but distance education was limited to receiving information and signals only. "I succeed in the theoretical parts of sign language courses above the expectation, but I do not think so on the practical side." At least," I wish practicing sign language would be in attending classrooms with direct communication and feedback between the student and the sign language teacher."
}

Some interviewees shared the same perception, which was "reduced the practice ability of sign language" (1). "Severely hindered me from practicing sign language" (23). If "teaching sign language continues attending classrooms, then there would be an opportunity for the student to practice the signs. Also, the lecturer and her colleagues correct the mistakes immediately and correctly as now we are deprived of needed feedback “ (19). Besides, participants $(5,7,8,15,18,20,23)$ reported that learning sign language needs continuous 
observation, the practice of the teacher's movements, and explanation accurately. Furthermore, that the teaching staffs, throughout this period, tried to teach sign language and worked hard to do so, but from their point of view, sign language needs a teacher in front of the students when explaining how to do it and evaluating the practice with others sufficiently, similar to those recommendation given by Baker-Shenk and Cokely (1991). Therefore, interacting with the faculty members during sign language learning and receiving direct, immediate, and face-to-face feedback with other students is one of the advantages of attending education (traditional) limited by online learning. Learning sign language requires intensive and direct observation to ensure the signs are made correctly in the proper position.

Sign language needs to be learned with enthusiasm, and the lack of competition among learners caused some interviewees to feel uninterested and unmotivated enough to progress in learning signs. For example, the participants reported that e-learning reduced the passion for learning sign language because it needs visual, physical, and communication. Moreover, it depends on the movements of the hands and the body and facial expressions" (7); "As I learned sign language on mobile and during indirect lectures, I forget it quickly, and I expect I studied them, but because there is no enthusiasm or motivation, I feel lost" (12). Some other interviewees $(9,15,23)$ reported similar concerns that learning sign language online may make them unenthusiastic and quickly lose their attention. However, this limitation might be due to how the classrooms are instructed online or how students perceived and interacted with sign language training. Ware (2004) studied how students in a classroom for English as a Second Language participated in the web-based learning environment and found that students made their choices in ways that reflected their previous experiences with technology and writing and how they view themselves as students and writers, and whether they feel comfortable with their peers in the classroom. Therefore, some faculty members faced some challenges like unenthusiastic and unmotivated factors at this period during distance learning, as they have not experienced this type of learning (in the sample of this study), as they used to receive their education (particularly sign language) in the face to face, collective, and competitive environments. However, suddenly because of a pandemic, they found themselves independent learners who must find a way to practice the signs by themselves.

One of the common difficulties in learning sign language online reported by the interviewees is the lack of confidence in using sign language as they feel unconfident about their ability to interact with their future deaf students. For example, participants reported, " it would be difficult to apply what learned from distance education in the field training, especially in terms of diagnosing a child's condition. They were able to communicate well with their families as they mentioned, "they were not confident about what they learned from the distance learning. (13) because of the lack of application in front of the lectures and other students concerns me to see whether the signal I apply is correct or not; hence, I am not confident I can do it" (14); and that "distance education also keeps the student's fear in her mind regarding signs, meaning that she would not be able to appear with complete confidence in front of the deaf students later on" (19). One of the strategies implemented in face-to-face sign language learning is to ask students to practice sign language under the lecture's observation, immediate feedback, and correction and sometimes invite deaf volunteers to practice their sign language. It may increase students' enthusiasm and become more confident about their sign language learning and application, as they are interested in their new learning and practice, especially when they learn new signs, which allow them to feel confident and progress sign learning seriously and interactively.

Learning sign language requires observation and imitation of the movements of the hands and the body as well as facial expressions; however, this was reported to be highly limited in learning sign language through online tools, although online video calls were used sometimes by some lectures to show students how to do the signs $(7,19,21,23)$. Understanding body language and facial expression is not only a necessary part of practicing sign language, but it is needed to fully pay attention to other signs to help in the process of reading other's body language, such as the context in which those signals occurred as we must view these signals as an integrated group to communicate well with the deaf people. In sign languages, signs are made on the hands, such as for emotions but, simultaneous facial expressions are compulsory for effective communication as facial expressions should be congruent with the hands' movements for the meaning to be conveyed 
(Denmark, 2011; Emmorey, 2001; Goldstein, Sexton, \& Feldman, 2000). Therefore, to form a clear sign language reading, learners must learn many nonverbal movements that deaf use and their meanings vary and change according to time, place, and context. Thus, some participants this as a limitation of online learning regardless of video calls and teaching tools that use online video calls.

On the other hand, some interviewees reported positive sign learning outcomes through online tools used during the COVID-19 crisis and the movement to e-online. For example, it has helped them to reform their opinion and experience of online learning, which led them to change their perception of online learning in general, as they found it helpful and valuable for practicing technical skills and can be implemented in their future work to provide their future students with enough skills to process what they learn. Although sign language may not require high technical skills, it would be helpful to maintain communication and interaction with deaf students. For example, two of the participants (\# 10 \& 18) stated that distance education helped to give them the ability to deal with different technological means that they may not be able to deal with in the same way through traditional education. This turns to online tools, developing their technical skills, and learning how to avoid technical disruptions regardless of the place and time. Further investigation with the interviewee of how this related to teacher-preparation programs shows that their technical skills are required to be accepted as they considered it one of the standards to get a good job and utilize online learning and teaching. Therefore, the COVID-19 crisis and the movement to online teaching tools may have contributed to change their perception of e-learning and developed their technical skills.

Other interviewees thought one of the significant impacts of this phenomenon is that it equips them with self-education and self-leaning as learning now relies on self-interest more than in traditional face-to-face learning. For example, one of the interviewees stated a person who has enough "motivation and enthusiasm to learn signs something would not hinder his learning in the presence of other distractions or obstacles regardless of it is direct or on distance" (15). Another interviewee indicated, "Education and learning at this period of years and with technological tools and live internet will not stop as intrinsic motivation will make learning accessible at any time and any circumstance" (18), and that "whoever wanted to learn sign language will seek to obtain it in every case and under any circumstance and wherever he was" (23). Thus, some participants thought that learning anything, including sign language, can be done personally. Self-learning is anything that a person can learn outside a classroom environment independently without teaching or following curriculums or examinations, and self-learning efforts cannot be measured because the goal is not how well a person performs in an exam but is to be satisfied with the learned knowledge (Ibabe \& Jauregizar, 2010; Phung, 2011). Therefore, E-learning is characterized by providing an opportunity for self-learning at any time and place and developing the students' abilities to sign and solve problems, make decisions, and facilitate communication on a comprehensive level independently.

Among the benefits of online learning stated by some of the interviewees is that it creates an interactive and accessible environment and atmosphere between the faculty member and the learner and develops students' abilities, and provides them with new skills that are appropriate for the environment in which they live and enable them to serve society. For example, some participants stated, "it helped me saving time in learning as it becomes easier and more accessible especially in respect to duties and requirements" (6), "I can now concentrate without disturbance and distraction, such as in the past if we were attending a class" (16), and "I think it made learning so much convenient and concrete as the used sites provided all the necessary means to convey information and display it in audio and video. "(17). Similarly, Kotzer and Elran (2012) found that the perception of students who used web-based homework and testing was very positives as it allows collaborative interaction among students.

Furthermore, preventing being afraid of being wrong or making a mistake is one of the benefits of online learning reported by the interviewees who reported that she could practice the sign language without hesitation or afraid of making the signs wrong $(2,24)$. It has been reported as an advantage of online learning in English acquisition classroom (Yao, 2017). Therefore, an online learning environment may help maintain students' psychosocial state as it allows them to practice language learning without the fear of being judged by mistakes. 
Finally, some of the interviewees' advantages are returning to lecture recording, and practice sings. Faculty in some educational institutions were required to record the lectures by video or audio and upload them so that the student can return to them when needed, especially to those who may not have immediate access to the internet. Two of the interviewees (14 \& 16) reported thoughts this is helpful as they can return to these recorders later to understand and review what the teacher said in the lecture and that they " can return to them at any time even during the tests period" (16). Harrison (2020) studied students' and teachers' attitudes to teaching videos used for distance learning and found that many students like and watch the videos. Hence, these recorded videos can be a tool for continuous learning, so sign language teachers should make wiser pedagogical decisions about when and how to use videos to achieve their goals and be available e-resources.

\section{CONCLUSION}

This study aimed to uncover strengths and weaknesses in online learning as perceived by students and concluded that the most strengths factors for their e-learning are the quality of course design, the ease of using online technologies, time management, and performing duties tasks at any time. Therefore, university faculty members should work immediately on the following reported disadvantages, difficulties, and concerns to overcome the possible shortcoming in the teachers-preparation program, the deafness path.

Participants reported multiple disadvantages, difficulties, and concerns of learning sign language through online tools used during the COVID-19 crisis and the movement to e-online. It has limited their engagement with other learners and the faculty members and caused restrictions on practicing sign language. Participants felt uninterested and unmotivated to progress in learning and to practice sign language through online tools due to the lack of competition among learners. Some interviewees thought that e-learning made them feel unconfident of their ability to interact with their future deaf students due to the lack of using sign language and ability to observe and imitate the movements of the hands and the body and facial expressions.

On the other hand, participants reported four main advantages of sign learning through online tools used during the COVID-19 crisis and the movement to e-online. It has helped them change their perception of elearning and developed their technical skills, which is useful for their career requirements. E-online helps them learn and use self-education and self-learning skills to become independent sign language learners. Eonline created an interactive and accessible atmosphere between the faculty member and the learner to interact with each other easily. Learners can return to the lecture recording to practice sign languages after the lecture, giving the instructor a chance to master sign learning. E-online tools allow learners to learn and practice sign language without being afraid of making mistakes or being judged by others.

The COVID-19 crisis has had a significant impact on learning and pre-service teachers' preparation programs, but the extent of the impact is not well defined, especially in sign language learning. The scholarly significance of this study is that it provided the theoretical foundation for using sign language through e-learning to understand how it can be strategically utilized in the future. Another significance of this study is that it explained what was not reported by existing studies through the effectiveness of using e-learning of sign language. It is also significant that this study objectively illuminated the difficulties reported by students so that they can be overcome in future practice. The risk of biological gender differences may not be cleared as this study was limited to one gender, females. However, it can be a foundation of moving to e-learning of sign language. Future studies are recommended to investigate further how can e-learning be used in teaching sign language.

\section{RECOMMENDATIONS}

This study reported several difficulties the sign language learners faced during the COVID-19 crisis and the movement to e-online, which challenges university faculty members working on teachers-preparation programs. These limitations may be due to students are not used to this type of learning and suddenly turns their education into "online" learning, away from the university classrooms, which by its nature stimulates study, discussion, and teamwork. Educators indicate that most students are good learners if they possess the 
necessary competence and motivation (Joe, Hiver, \& Al-Hoorie, 2017; Knoors \& Marschark, 2014), so we should go back to the pedagogical strategies that have proven effective in encouraging and motivating students to learn and implemented them effectively. One of these strategies is to focus on learners' strengths and avoiding their weaknesses, as educators believe that focusing on learners' strengths will help achieve academic and emotional development and progress sign language learning, in contrast to focusing on weaknesses that cause only frustration, anxiety and unwillingness to learn or practice sign language. Perhaps the diversification of learning styles is one of the essential strategies that educators recommend motivating students to learn, as the human being, in general, uses different senses to receive and process information and learn it (Ally, 2004).

It is a well-established aspect in educational sciences that students differ in their preference for using these senses. Some of them are visual, some are auditory, and some are sensory kinesthetic (Gilakjani, 2012). The visual prefers reading, watching, and using pictures, maps, tables, and charts, and the auditory one prefers to listen to audio recordings and form sentences and songs about what is taught. In contrast, the sensory kinesthetic prefer to touch and feel things physically when learning-consider this when learning and practicing sign language may provide each student with his/her preference and allow them to learn effectively. From an educational perspective, the diversification in learning styles helps in remembering and understanding and raises motivation and enthusiasm (Pritchard, 2017). While the learners watch the signs computerized or televised, we encourage them to listen carefully and write notes and necessary information such as the body language position or facial expression, keywords. Moreover, when they finish the lecture, they could be encouraged to pronounce them out loud to others. It would enable them to carry out the required learning and practices conveniently.

The researcher recommends implementing web and phone applications to practice sign language, similar to those used to teach English as a second language and allow learners to interact formally and informally with native speakers. Any language required continuous practice, which is a good time to do so. Digital gamebased learning is beneficial for unmotivated students or those with a lack of interest in learning activities (Paraskeva, Mysirlaki, \& Papagianni, 2010); thus, it can be used as a tool to deliver sign language learning. Furthermore, universities and policymakers need to use this period effectively, the transition to e-learning, overcome the obstacles facing students and lectures, and provide training lectures on how to use this type of learning to teach and practice sign language. It is due to the importance of using educational e-learning platforms as innovative teaching methods that use online means to deliver and display sign language lessons through virtual learning applications and learning with augmented reality using intelligent panels in the future.

Funding: Author received no financial support for the research and/or authorship of this article.

Declaration of interest: Author declares no competing interest.

Data availability: Data generated or analysed during this study are available from the author on request.

\section{REFERENCES}

Abdel-Fattah, M. A. (2005). Arabic sign language: a perspective. Journal of Deaf Studies and Deaf Education, 10(2), 212-221. https://doi.org/10.1093/deafed/eni007

Adedoyin, O. B., \& Soykan, E. (2020). COVID-19 pandemic and online learning: the challenges and $\begin{array}{llll}\text { opportunities. Interactive Learning 1-13. } & \end{array}$ https://doi.org/10.1080/10494820.2020.1813180

Alajlan, M. (2017). Knowledge and attitudes of faculty members at a Saudi university toward deaf and hard of hearing students in higher education (Doctoral dissertation). University of New Orleans, New Orleans, LA.

Aldabas, R. A. (2015). Special education in Saudi Arabia: History and areas for reform. Creative Education, 6(11), 1158. https://doi.org/10.4236/ce.2015.611114 
Ally, M. (2004). Foundations of educational theory for online learning. Theory and Practice of Online Learning, 2, 15-44.

Alnahdi, G., \& Anastasiou, D. (2020). Recruitment Practices for Special Education Faculty: Implications for Saudi Universities. SAGE Open, 10(3), 1-8. https://doi.org/10.1177/2158244020948844

Alwedinani, J. (2016). Gender and subject choice in higher education in Saudi Arabia (Doctoral dissertation). University of York, Heslington.

Baker-Shenk, C. L., \& Cokely, D. (1991). American Sign Language: A teacher's resource text on grammar and culture. Gallaudet University Press.

Bryman, A. (2016). Social research methods (5th Ed.). Oxford University Press.

Creswell, J. W. (2007). Qualitative inquiry and research design: Choosing among five approaches. Sage Publications.

Creswell, J. W., \& Creswell, J. D. (2018). Research design: Qualitative, quantitative, and mixed methods approach. Sage publications.

Darling-Hammond, L., \& Bransford, J. (Eds.) (2005). Preparing teachers for a changing world: What teachers should learn and be able to do. Jossey-Bass.

Denmark, T. A. (2011). Do deaf children with Autism Spectrum Disorder show deficits in the comprehension and production of emotional and linguistic facial expressions in British Sign Language? (Doctoral dissertation). UCL (University College London).

Dewey, J. (1921). Reconstruction in philosophy. University of London Press. https://doi.org/10.1037/14162000

Dewey, J. (2004; original in 1960). Democracy and education. Aakar Books.

Dulamă, M. E., \& Ilovan, O. R. (2020). Online university education during the COVID-19 pandemic. How efficient are the adapted instruction models?. Journal of Educational Sciences \& Psychology, 10(2), 92111.

Emmorey, K. (2001). Language, cognition, and the brain: Insights from sign language research. Psychology Press. https://doi.org/10.4324/9781410603982

Gilakjani, A. P. (2012). Visual, auditory, kinaesthetic learning styles and their impacts on English language teaching. Journal of Studies in Education, 2(1), 104-113. https://doi.org/10.5296/jse.v2i1.1007

Goldstein, N. E., Sexton, J., \& Feldman, R. S. (2000). Encoding of facial expressions of emotion and knowledge of American Sign Language. Journal of Applied Social Psychology, 30(1), 67-76. https://doi.org/10.1111/j.1559-1816.2000.tb02305.x

Harrison, T. (2020). How distance education students perceive the impact of teaching videos on their learning. Open Learning: The Journal of Open, Distance and e-Learning, 35(3), 260-276. https://doi.org/10.1080/02680513.2019.1702518

Hunt, J., \& Eisenberg, D. (2010). Mental health problems and help-seeking behavior among college students. Journal of Adolescent Health, 46(1), 3-10. https://doi.org/10.1016/j.jadohealth.2009.08.008

Ibabe, I., \& Jauregizar, J. (2010). Online self-assessment with feedback and metacognitive knowledge. Higher Education, 59(2), 243-258. https://doi.org/10.1007/s10734-009-9245-6

Joe, H. K., Hiver, P., \& Al-Hoorie, A. H. (2017). Classroom social climate, self-determined motivation, willingness to communicate, and achievement: A study of structural relationships in instructed second language settings. Learning and Individual Differences, 53, 133-144. https://doi.org/10.1016/j.lindif.2016.11.005 
Johnson, B., \& Christensen, L. (2012). Educational research. SAGE Publications.

Kang, D. Y., \& Martin, S. N. (2018). Improving learning opportunities for special education needs (SEN) students by engaging pre-service science teachers in an informal experiential learning course. Asia Pacific Journal of Education, 38(3), 319-347. https://doi.org/10.1080/02188791.2018.1505599

Knoors, H., \& Marschark, M. (2014). Teaching deaf learners: Psychological and developmental foundations. Oxford University Press. https://doi.org/10.1093/acprof:oso/9780199792023.001.0001

Kotzer, S., \& Elran, Y. (2012), learning and teaching with Moodle-based E-learning environments, combining learning skills and content in the fields of Math and Science \& Technology. Proceedings of the 1st Moodle Research Conference (MRC2012) (pp. 122-131).

Meir, I., Sandler, W., Padden, C., \& Aronoff, M. (2010). Emerging sign languages. Oxford handbook of deaf studies, language, and 267-280. https://doi.org/10.1093/oxfordhb/9780195390032.013.0018

Middleton, A., Niruban, A., Girling, G., \& Myint, P. K. (2010). Communicating in a healthcare setting with people who have hearing loss. BMJ: British Medical Journal, 341, 726-729. https://doi.org/10.1136/bmj.c4672

Paraskeva, F., Mysirlaki, S., \& Papagianni, A. (2010). Multiplayer online games as educational tools: Facing new challenges in learning. Computers \& Education, 54(2), 498-505. https://doi.org/10.1016/j.compedu.2009.09.001

Phung, L. F. (2011). Self-regulated learning in an E-learning Environment in a Malaysian University (Doctoral dissertation). Curtin University.

Pritchard, A. (2017). Ways of learning: Learning theories for the classroom. Routledge. https://doi.org/10.4324/9781315460611

Rohman, M., Marji, D. A. S., Sugandi, R. M., \& Nurhadi, D. (2020). Online Learning in Higher Education During COVID-19 Pandemic: Students' Perceptions. Journal of Talent Development and Excellence, 12(2s), 3644-3651.

Rose, S. (2006). How do we fix schools? American School Board Journal, 193(9), 15.

Rousseau, S., \& Deschacht, N. (2020). Public awareness of nature and the environment during the COVID-19 crisis. Environmental and Resource Economics, 76(4), 1149-1159. https://doi.org/10.1007/s10640020-00445-w

Rowan, L., Bourke, T., L’Estrange, L., Lunn Brownlee, J., Ryan, M., Walker, S., \& Churchward, P. (2020). How Does Initial Teacher Education Research Frame the Challenge of Preparing Future Teachers for Student Diversity in Schools? A Systematic Review of Literature. Review of Educational Research, https://doi.org/10.3102/0034654320979171

Rubin, H. J., \& Rubin, I. S. (1995). Qualitative interviewing (2nd ed.). Sage Publications.

Sahoo, A. K., Mishra, G. S., \& Ravulakollu, K. K. (2014). Sign language recognition: State of the art. ARPN Journal of Engineering and Applied Sciences, 9(2), 116-134.

Samuseviča, A., \& Striguna, S. (2017). The Development of Teachers' Pedagogical Competence in the Process of Self-education at the University. International Journal on Lifelong Education and Leadership, 3(2), 39-46.

Son, C., Hegde, S., Smith, A., Wang, X., \& Sasangohar, F. (2020). Effects of COVID-19 on college students' mental health in the United States: An interview survey study. Journal of Medical Internet Research, 22(9), e21279. https://doi.org/10.2196/21279 
Song, L., Singleton, E. S., Hill, J. R., \& Koh, M. H. (2004). Improving online learning: Student perceptions of useful and challenging characteristics. The Internet and Higher Education, 7(1), 59-70. https://doi.org/10.1016/j.iheduc.2003.11.003

Thomas, L. (Ed.). (2013). What is Canadian about teacher education in Canada? Multiple perspectives on Canadian teacher education in the twenty-first century. Canadian Association for Teacher Education.

Topping, K., Douglas, W., \& Robertson, D. (2020). The Effectiveness of Online and Blended Learning from Schools: A Scoping Review. The University of Dundee. Retrieved 5 January 2021 from https://discovery.dundee.ac.uk/ws/portalfiles/portal/51952060/scoping_review.pdf

Toquero, C. M. (2020). Challenges and Opportunities for Higher Education Amid the COVID-19 Pandemic: The Philippine Context. Pedagogical Research, 5(4), em0063. https://doi.org/10.29333/pr/7947

Trombly, C.E. (2020). Learning in the time of COVID-19: capitalizing on the opportunity presented by the pandemic. Journal of Professional Capital and Community, 5(3/4), 351-358. https://doi.org/10.1108/JPCC-05-2020-0016

Umarova, Z. (2020). Modern and Innovative Approaches to the Organization of Students' Self-Education in Higher Educational Institutions. Journal La Edusci, 1(4), 5-8. https://doi.org/10.37899/journallaedusci.v1i4.223

Vasile, C. (2020). Editor's note: A psychology of crisis. Journal of Educational Sciences \& Psychology, 10(1), 12.

Ware, P. D. (2004). Confidence and competition online: ESL student perspectives on web-based discussions in the classroom. Computers and Composition, 21(4), 451-468. https://doi.org/10.1016/S87554615(04)00041-6

Yao, C. (2017). A case study on the factors affecting Chinese adult students' English acquisition in a blended learning environment. International Journal of Continuing Engineering Education and Life-Long Learning, 27(1-2), 22-44. https://doi.org/10.1504/IJCEELL.2017.080993

Correspondence: Omar Alawajee, Department of Special Education, College of Sciences and Arts, Qassim University, Ar Rass, Saudi Arabia. E-mail: o.alawajee@qu.edu.sa 